\title{
Reclaim of Synthetic Rutile Fines Produced In Ilmenite Beneficiation Process by Agglomeration
}

\author{
V. S. Gireesh · G. Lijith · I. K. Shaju · P. K. Manikuttan
}

Titanium pigment Unit, The Kerala Minerals and Metals Limited, Sankaramangalam, Chavara, Kollam, Kerala, India 691583.

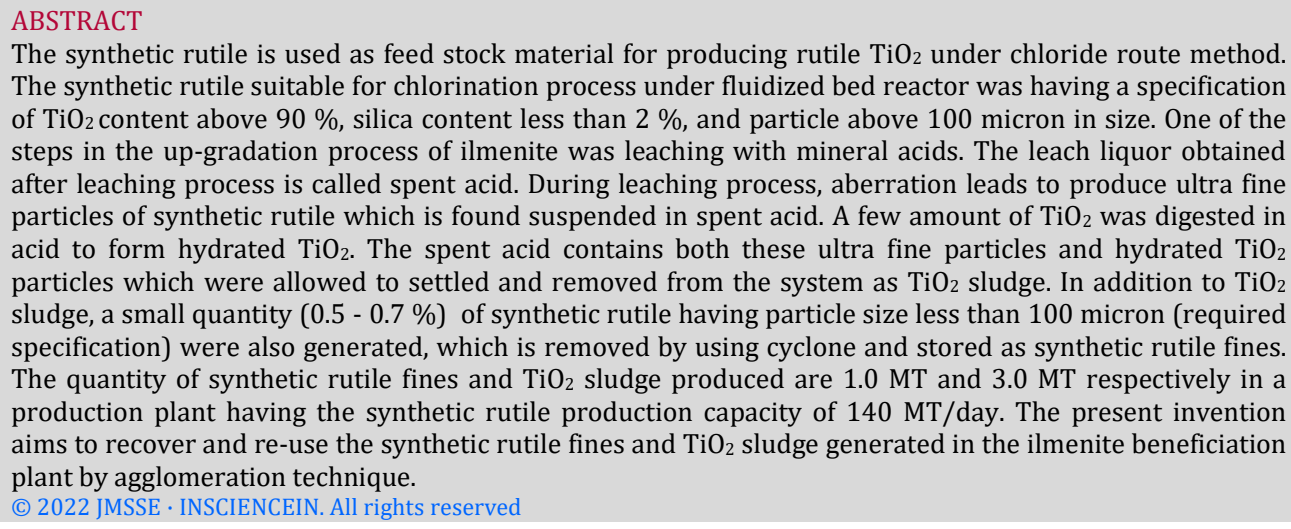

\section{Introduction}

Titanium dioxide, a white pigment finds wide application in paint, plastic, catalytic, ink, textiles, ceramic etc., due to its excellent pigmentary properties [1-4]. The band gap of $\mathrm{TiO}_{2}$ pigment is ranging from $3.0-3.2 \mathrm{eV}$, which makes its wide application in the field of photocatalysis [5-7]. Anatase, rutile and brookite are the three different crystalline forms of $\mathrm{TiO}_{2}$ among which the rutile is the most stable form [8]. Commercial production of titanium dioxide is either by sulphate or chloride process with small extent of other processes like solvent extraction, electrochemical process etc [9-11]. The chloride process produces rutile titanium dioxide and sulphate process technology used for producing both anatase and rutile titanium dioxide. The pigmentary property of rutile titanium dioxide is superior compared to anatase, but for photo-catalysis the anatase is superior due to its large band gap of $3.2 \mathrm{eV}$ [6]. For pigmentary properties, the rutile pigment produced by chloride route is superior compared to rutile pigment produced by sulphate process. In the world scenario, more than $60 \%$ of titanium dioxide production is through chloride route. The chloride route uses ilmenite, titanium slag, synthetic rutile, natural rutile as feedstock material. Synthetic rutile is the most preferred material compared to other feedstock materials due to its high $\mathrm{TiO}_{2}$ content (92$95 \%)$, less other impurities like iron oxide (2-3\%), silica (0.5-1.5\%) alumina ( 0.5-1.0\%) etc. There are many technologies used to upgrade the $\mathrm{TiO}_{2}$ values in ilmenite, but the commercial production still relay on either Becher process or Benalite process. In both processes, the ilmenite is subjected to carbothermic reduction followed by leaching to reduce the iron values and upgrade the ilmenite to synthetic rutile [12].

The synthetic rutile is used as the feed stock for chlorination process for producing titanium tetrachloride.
The titanium tetra chloride on subjected to oxidation with oxygen at high temperature to produce rutile titanium dioxide pigment. The chlorination process is carried out in a fluidized bed reactor and the particle size of the feed stock material is very critical in fluidization process. The draft velocity inside the chlorinator leads to the carryover of the ultra fine particles (below 100 micron) and hence these ultra fine particles will not get enough residence time for getting chlorinated. The ultra fine synthetic rutile particle does not produce titanium tetra chloride and it is removed from the chlorination unit in cyclonic separation system as dust particles. These fines enhances the generation of Effluent Treatment Plant (ETP) solid in titanium dioxide plant.

The Q-grade ilmenite (Quilon grade) which is one of the best quality of ilmenite available contains nearly $60 \%$ of $\mathrm{TiO}_{2}$. The fine fraction ( $<100$ micron) in this ilmenite is about $5 \%$. This ilmenite contain $25 \%$ of ferric oxide and $10 \%$ of ferrous oxide and balance with other impurities like silica, alumina etc. The $\mathrm{Q}$ grade ilmenite is available in the costal areas of Kollam district in Kerala, India.

The ferric content in the ilmenite is reduced to ferrous during carbothermic reduction at $1000{ }^{\circ} \mathrm{C}$. The reduced ilmenite was subjected to hydrochloric acid leaching to remove the $90 \%$ of iron content in reduced ilmenite. The reduced ilmenite after removal of $90 \%$ of iron content is called leached ilmenite. The leached ilmenite is then heated at $600{ }^{\circ} \mathrm{C}$ in a rotary kiln to convert it to synthetic rutile which contain about $92-95 \%$ of $\mathrm{TiO}_{2}$. In addition of the existing $5 \%$ fines (less than 105 micron size particle) in ilmenite, the above process of carbothermic reduction and leaching also generate fines content in the synthetic rutile. A fraction of the fines generated will carryover along with the spent acid (leach liquor), where us the balance fraction of fines are removed from the synthetic rutile after 
calcination, through cyclone system. The fines carried-over with the spent acid were settled in storage tanks by giving settling time. The fines free spent acid was feed to acid regeneration plant to regenerate to hydrochloric acid from the spent acid and again used for leaching process. The settled fines are removed as sludge which is neutralized and stored along with ETP solid. The fines fraction removed from cyclone is also is dumped along with ETP. Almost 1.0 MT of cyclone separated fines and 3.0 MT of $\mathrm{TiO}_{2}$ sludge are generated in $140 \mathrm{MT} /$ day synthetic rutile production. Presently the 4.0 MT of these fines are losing per day. Moreover, these fines increases the volume of ETP solid generated. The present invention is related to development of a selective self sintering (agglomeration) technology for size improvement of synthetic rutile fines to usable range in fluidized bed reactor producing titanium tetrachloride. Moreover, by implementing this technology, the Ilmenite Beneficiation plant will become a zero effluent discharge system.

\section{Experimental \\ Materials}

The typical composition of Q-grade ilmenite is given in Table 1 . The $\mathrm{TiO}_{2}$ content in the Q-grade ilmenite is $60 \%$, which make its superiority over other ilmenite. The high ferric content compared to ferrous showed that this type of ilmenite was highly weathered ilmenite (more aerial oxidation). The alteration of ilmenite was occurred during weathering process there by crystallography changes to pseudo brookite, pseudo rutile, rutile etc. The Typical particle size of the $\mathrm{Q}$ grade ilmenite is given Table 2 .

Table1: Typical composition of Q grade ilmenite

\begin{tabular}{ccc}
\hline Sl. No & Constituents & Percentage \\
\hline 1 & $\mathrm{TiO}_{2}$ & 60 \\
2 & $\mathrm{Fe}_{2} \mathrm{O}_{3}$ & 25 \\
3 & $\mathrm{FeO}$ & 10 \\
4 & $\mathrm{SiO}_{2}$ & 1.5 \\
5 & $\mathrm{Al}_{2} \mathrm{O}_{3}$ & 1.0 \\
6 & $\mathrm{~V}_{2} \mathrm{O}_{5}$ & 0.12 \\
7 & $\mathrm{Cr}_{2} \mathrm{O}_{3}$ & 0.12 \\
8 & $\mathrm{ZrO}_{2}$ & 0.30 \\
5 & $\mathrm{Nb}_{2} \mathrm{O}_{5}$ & 0.20 \\
\hline
\end{tabular}

Table 2: Typical particle size of Q grade ilmenite

\begin{tabular}{ccc}
\hline ASTM Mesh & Size in Micron & Percentage \\
\hline+30 & $>600$ & 3 \\
$-30+60$ & $600-250$ & 32 \\
$-60+100$ & $250-150$ & 35 \\
$-100+140$ & $150-105$ & 25 \\
-140 & $<105$ & 5 \\
\hline
\end{tabular}

The fine fraction in ilmenite (less than 105 micron in size) is $5 \%$. These fines will loss in the up gradation process either as $\mathrm{TiO}_{2}$ sludge or as synthetic rutile fines through cyclone.

\section{Carbo-thermic reduction}

The ilmenite was subject to carbo-thermic reduction using petroleum coke as reductant. The dimension of the kiln was 30 meter length and 2 meter diameter. The temperature inside the kiln will be around $1000{ }^{\circ} \mathrm{C}$. The ilmenite to petroleum coke feed ratio to the kiln is 10:1. The kiln rotates at a speed of $1 \mathrm{rpm}$ and thereby providing a residence time of 1.5 hour for the ilmenite reduction reaction. In reduced ilmenite, $90 \%$ of ferric ions are converted to ferrous ions. There will be no changes in $\mathrm{TiO}_{2}$

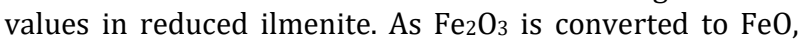

there will be a slightly weight loss occurred in quantity of ilmenite.

\section{Leaching process}

The leaching process of reduced ilmenite is carried out by using hydrochloric acid in a closed digester system. The leaching process is a pressurised one with a reaction temperature of around $142{ }^{\circ} \mathrm{C}$ and pressure $3.5 \mathrm{~kg} / \mathrm{cm}^{2}$. The pressure was created by charging steam in to the system continously. The hydrochloric acid after leaching process is called spent acid, which will again convert to hydrochloric acid in acid regeneration plant and hence reused. The leached ilmenite contains about $90-95 \%$ of $\mathrm{TiO}_{2}$ values. The fines already in the ilmenite as well as the fines generated in the beneficiation process were removed from the system either through spent acid or in cyclone discharge after calcinations. The spent acid is stored in huge tanks called settling tanks where sufficient time is given for settling of fines in spent acid before its reprocessing in acid regeneration plant. The settled fines is removed from the storage tanks as sludge which is neutralized and then stored in ETP sludge pond.

\section{Characterization studies}

The particle size distribution of the raw materials were measured by using Microtrac particle size analyzer. The crystallographic nature of the material was determined by taking XRD spectra using Rigaku XRD instrument. The zeta potential was measured by using Malven Zetasizer Z590 instrument.

\section{Results and Discussion Characterization of Materials}

The synthetic rutile fines having $\mathrm{aTiO}_{2}$ value of $92.5 \%$ and $\mathrm{TiO}_{2}$ sludge was having a $\mathrm{TiO}_{2}$ content of $93.6 \%$. Both the $\mathrm{TiO}_{2}$ sludge and synthetic rutile fines were having particle size $<100$ micron in size. The $\mathrm{TiO}_{2}$ sludge also contains small amount of titanium oxy chloride, hydrated $\mathrm{TiO}_{2}$ etc., produced by the leaching reaction of ilmenite with hydrochloric acid. Figure 1 showed the photographs of decanted $\mathrm{TiO}_{2}$ sludge and synthetic rutile fines.

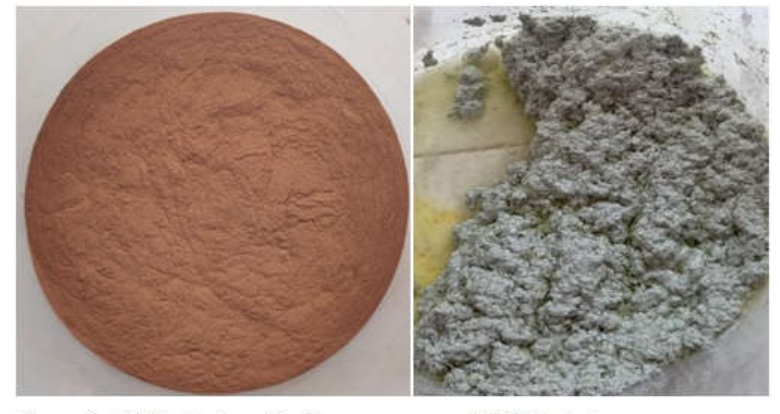

Figure 1: (a) Synthetic rutile fines

(b) $\mathrm{TiO}_{2}$ sludge

Figure 1: Photographs of decanted $\mathrm{TiO}_{2}$ sludge and synthetic rutile fines

\section{Particle size distribution}

The particle size distribution of synthetic rutile fines and $\mathrm{TiO}_{2}$ sludge were shown in Figure 2.0. A wide distribution of particle was noticed in both cases. The particle sizes of both materials were ranged from 0.5 micron to 100 micron in size. The average particle size of synthetic rutile fines was 8.746 micron and $\mathrm{TiO}_{2}$ sludge was 2.946 micron. Both synthetic rutile fines and $\mathrm{TiO}_{2}$ sludge were having particle size less than 100 micron and hence cannot be directly 
used in chlorination process, unless the size of these fines were enhanced by agglomeration.

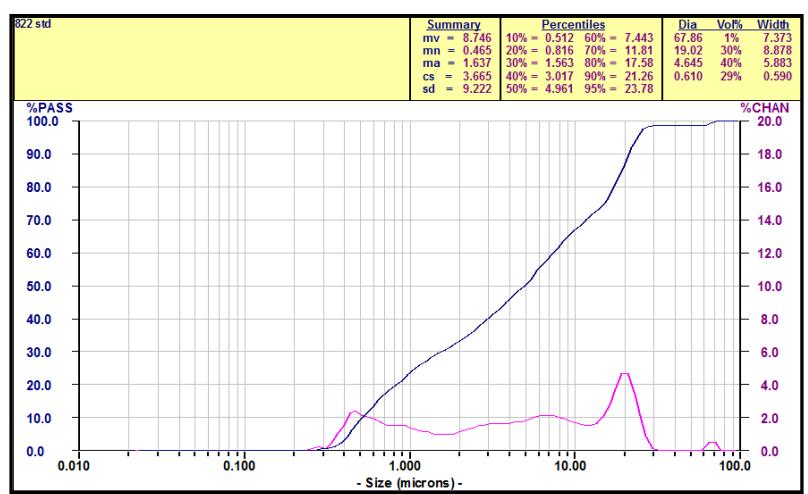

(a)

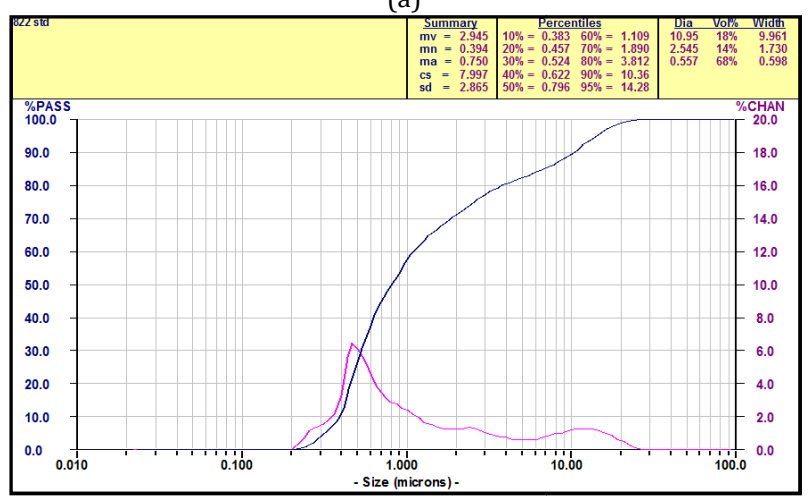

(b)

Figure 2: (a) synthetic rutile fines (b) $\mathrm{TiO}_{2}$ sludge

Crystallographic nature

The XRD spectrum of synthetic rutile fines and $\mathrm{TiO}_{2}$ sludge were shown in Figure 3.

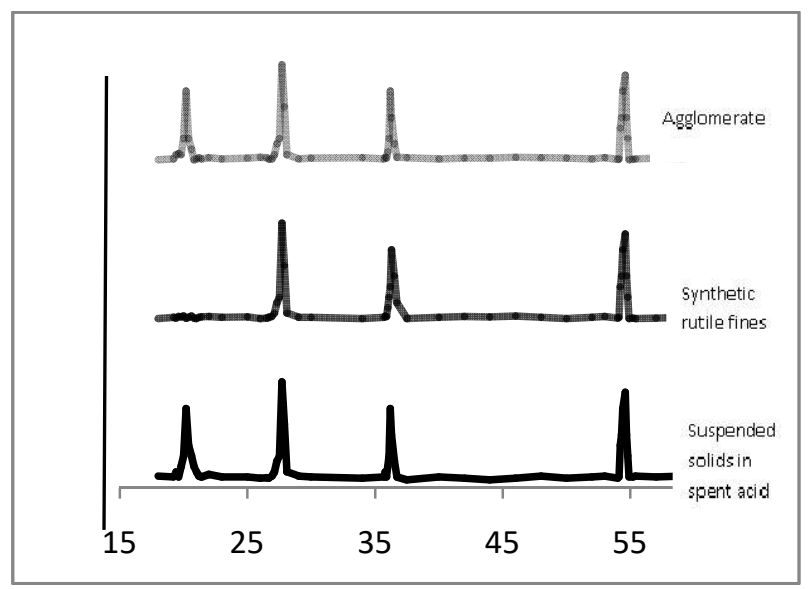

Figure 3: XRD pattern

As expected, the synthetic rutile fines having a XRD peak as same as that of rutile peak $\left(27.5^{\circ}, 36.2^{\circ}, 54.5^{\circ}\right)$.The XRD pattern of $\mathrm{TiO}_{2}$ sludge, showed an additional peak at 20.26 $\circ$. This peak is due to the presence of hydrated $\mathrm{TiO}_{2}$ present in the material. This hydrated $\mathrm{TiO}_{2}$ was produced by the closed pressurized leaching of the ilmenite with $\mathrm{HCl}$. The hydrated $\mathrm{TiO}_{2}$ will have a surface charge, confirmed by zeta potential, which enhances the agglomerate formation.

\section{Surface charge studies}

The zeta potential curves of both synthetic rutile fines and $\mathrm{TiO}_{2}$ sludge are shown in Figure 4(a) and 4(b). The zeta potential value of TiO2 sludge is $+35 \mathrm{mV}$, where the zeta potential value of synthetic rutile fines was $-21 \mathrm{mV}$. The zeta potential values between 0 to $\pm 5 \mathrm{mV}$ were having rapid coagulation tendency, the zeta potential lies between10 to $-35 \mathrm{mV}$ and +10 to $+35 \mathrm{mV}$ were having moderate coagulation tendency and zeta potential lies between -35 to $-65 \mathrm{mV}$ and +35 to $+65 \mathrm{mV}$ having poor coagulation tendency. The zeta potential of $\mathrm{TiO}_{2}$ sludge and synthetic rutile fines were lies between -10 to $-35 \mathrm{mV} /+10$ to +35 $\mathrm{mV}$ and it showed that both these material were having moderate coagulation tendency. The above study confirms that agglomeration is possible for these materials.

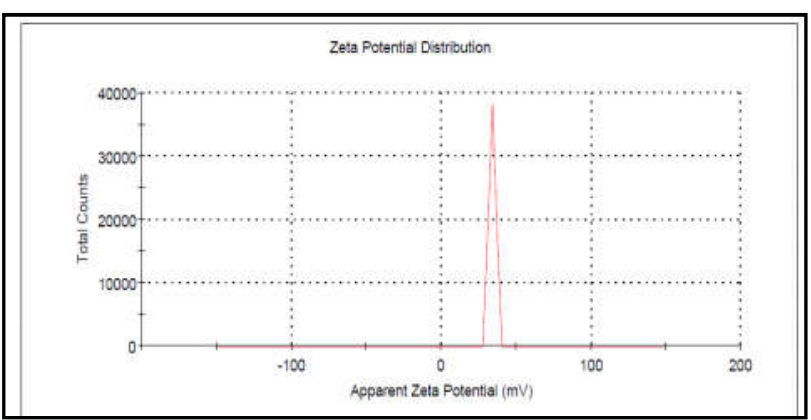

(a)

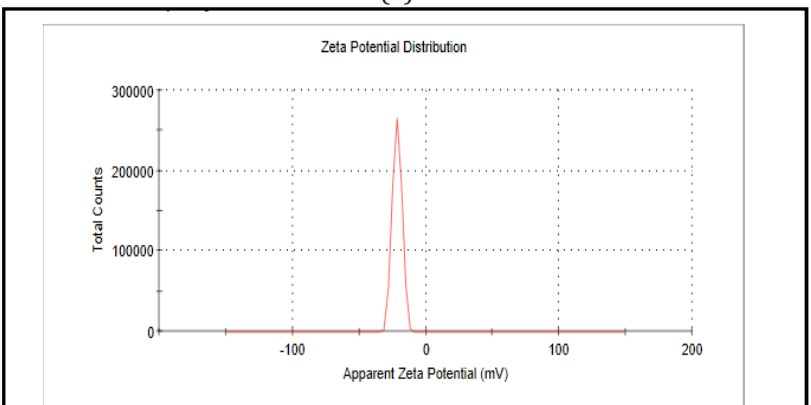

(b)

Figure 4: (a) Zeta potential ofTiO2 sludge, (b) zeta potential of Synthetic rutile fines

\section{Production of green agglomerate}

The synthetic rutile fines was mixed with a $\mathrm{TiO}_{2}$ sludge approximately in 1:1 ratio in a agitator fabricated by in house development methods or a pan mixer. The agitator base rotates at a speed of 10 to $100 \mathrm{rpm}$. A racket shaped agitator was provided internally which revolves around 50 rpm. Baffles were provided at suitable locations inside the vessel, which ensures proper mixing of synthetic rutile fines with $\mathrm{TiO}_{2}$ sludge and produces green agglomerate (GA)- Figure 5.

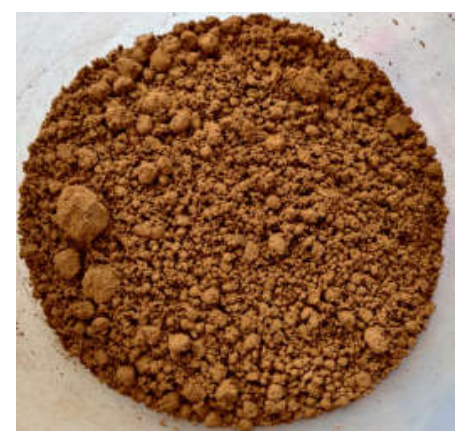

Figure 5: Photographs of Green agglomerate Production of sintered agglomerate

The schematic representation of sintering process was given in Figure 6. The GA was subjected to a thermal treatment in a rotating kiln, along with LI produced from IBP plant in 1:1 ratio, at a temperature of $600-800{ }^{\circ} \mathrm{C}$. The kiln is operated at a speed of $2 \mathrm{rpm}$. The residence time in 
the kiln was 2 hours. The outlet material from kiln was cooled by cooler which was operated by counter current flow of air. The cooler material was sieved in automatic vibrating screen of $2.0 \mathrm{~mm}$ mesh size to remove the larger material. The underflow obtained is the agglomerated sintered samples.

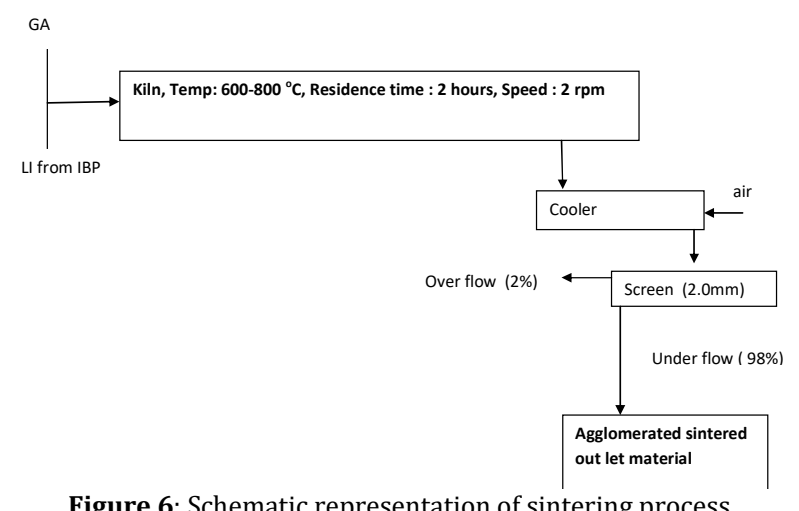

The products so formed were evaluated both for particle size and quality $\left(\mathrm{TiO}_{2}, \mathrm{Fe}_{2} \mathrm{O}_{3}\right.$ and $\left.\mathrm{SiO}_{2}\right)$. The results are given in Table-3. The particle size enhancement was noticed during the thermal treatment. The under sized fraction (less than 100 micron) was found to be around 23 $\%$ at all the temperatures studied. The agglomeration/sintering was found to be occurred inside the kiln having temperature of 600 to $800{ }^{\circ} \mathrm{C}$ and a residence time of 2 hours. The synthetic rutile produced was having $77 \%$ of particle size within the specification limit of synthetic rutile used for chlorination process in fluidized bed reactor. The $\mathrm{TiO}_{2}$ content in the synthetic rutile agglomerate was above $93.0 \%$, with silica around 1.0 $\%$, and $\mathrm{Fe}_{2} \mathrm{O}_{3}$ around $3.5 \%$. The specification of synthetic rutile used for chlorination were having $\mathrm{TiO}_{2}$ content of above $92 \%$, silica content of less than $2 \%$ and iron oxide less than $5 \%$. The synthetic rutile agglomerate produced meets the specification of the feed stock for chlorination process but the fines fraction of around $23 \%$, restricts its re-use as feed stock in chlorinator for producing titanium tetra chloride.

Table-3: Characterization of agglomerate obtained

\begin{tabular}{|c|c|c|c|c|c|c|c|c|}
\hline \multirow[t]{3}{*}{ Exp } & \multicolumn{8}{|c|}{ Characterization of calcined samples } \\
\hline & \multirow{2}{*}{$\begin{array}{l}\text { Temp. } \\
\text { (oC) }\end{array}$} & \multicolumn{3}{|c|}{ Particle size (micron), $\%$} & \multicolumn{4}{|c|}{ Composition (\%) } \\
\hline & & 420 & 150 & 100 & $<100$ & $\mathrm{TiO} 2$ & $\mathrm{SiO} 2$ & $\mathrm{Fe} 2 \mathrm{O} 3$ \\
\hline 1 & 600 & 30.60 & 21.51 & 25.47 & 22.42 & 93.2 & 1.1 & 3.4 \\
\hline 2 & 700 & 29.99 & 21.15 & 25.12 & 23.74 & 93.1 & 1.0 & 3.6 \\
\hline 3 & 800 & 28.57 & 22.14 & 26.98 & 22.31 & 93.2 & 1.1 & 3.5 \\
\hline
\end{tabular}

\section{Theory}

The synthetic rutile fines is having particle size less than 100 micron and apart from this, there is no quality difference between fines and synthetic rutile. Lower particle size of the fines restricts its use as feed stock in chlorination process. These fines generated by the aberration between particles during acid leaching. This fine behaves as free flowing material. On the other hand, the $\mathrm{TiO}_{2}$ sludge in spent acid was produced by the hydrochloric acid leaching and carried over along with the spent acid after leaching. A small amount of $\mathrm{TiO}_{2}$ in ilmenite also undergoes digestion in acid and produced titanium oxy chloride and hydrated titanium oxides. Hence the $\mathrm{TiO}_{2}$ sludge in spent acid contains titanium oxy chloride, hydrated precipitate of titanium oxide and the leached ilmenite fines. This sludge was having surface charge and forms coagulated mass in spent acid. This sludge is separated from the spent acid by giving sufficient settling time and draining the bottom part. While mixing the synthetic rutile fines with $\mathrm{TiO}_{2}$ sludge, the surface of the synthetic rutile fines will be soaked with the $\mathrm{TiO}_{2}$ sludge particles. This will create a surface charge and particles tend to agglomerate and will form green agglomerate. This green agglomerate on heating at elevated temperature to form sintered agglomerate of required size. The green agglomerate alone was heated in a kiln, the attrition was found to be on the higher side creating more fines. By using LI mixed GA the attrition rate inside the kiln will be minimized. The schematic representation of theory of agglomeration was given in Figure 7.

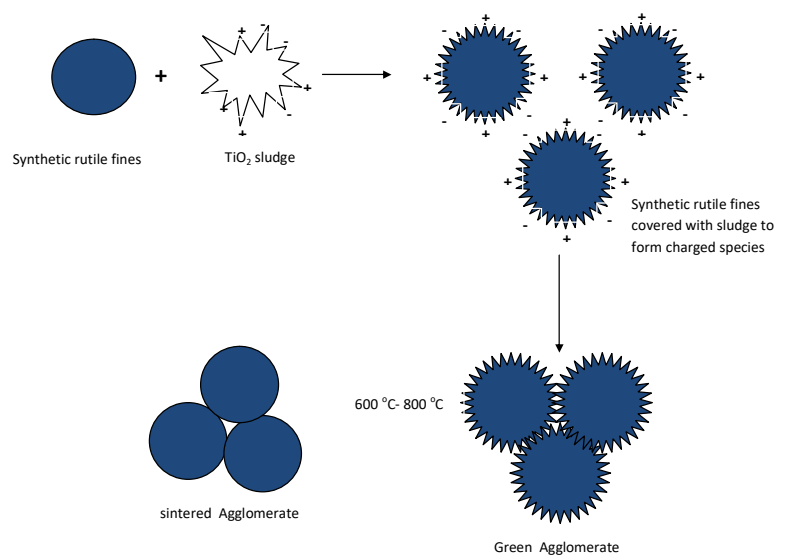

Figure 7: The schematic representation of theory of agglomeration

\section{Conclusions}

The present invention mainly relates to recover and re-use of synthetic rutile fines and $\mathrm{TiO}_{2}$ sludge generated in the ilmenite beneficiation plant. The quantity of synthetic rutile fines and $\mathrm{TiO}_{2}$ sludge produced were $1.0 \mathrm{MT}$ and 3.0 MT/day respectively in a synthetic rutile production plant having the synthetic rutile production capacity of 140 MT/day. The synthetic rutile suitable for chlorination process under fluidized bed reactor was having a specification of $\mathrm{TiO}_{2}$ content above $90 \%$, silica content less than $2 \%$, and particle size above 100 microns. The synthetic rutile fines and $\mathrm{TiO}_{2}$ sludge were having same properties as that of synthetic rutile used in chlorination process except in particle size (the required particle size of synthetic rutile for chlorination is above 100 micron in size). The particle size for both fines and sludge are below 100 microns in size and hence these materials were not suitable for chlorination process. Presently these materials were treated as waste and goes along with ETP solid generated in the $\mathrm{TiO}_{2}$ production plant. The agglomeration technology was successfully used to resize these materials suitable for chlorination process. By developing this technology, 4.0 MT of the synthetic rutile production will be increased per day. Moreover, the quantity of ETP solid generation is also decreased.

\section{References}

1. A.J. Haider, Z. N. Jameel, I. H. M. Al-Hussaini, Review on Titanium dioxide Application, Ener. Proc., 2019, 157, 17-29. https://doi.org/10.1016/j.egypro.2018.11.159

2. A.X. Gao,J. D. Bolt, A. A. Feng, Role of Titanium Dioxide Pigments in Outdoor Weathering of Rigid PVC Plastics, Rubber and Compos., 2008 37, 397-402. https://doi.org/10.1179/174328908X356545 
3. R.E. Day, The Role of Titanium Dioxide Pigments in the Degradation and Stabilisation of Polymers in the Plastics Industry. Pol. Deg. and Stab., 1990, 29, 73-92. https://doi.org/10.1016/0141-3910(90)90023-Z

4. M.M. Rahman, M. Solaiman, E. Khalil, Effect of Titanium Dioxide Treatment on the Properties of $100 \%$ Cotton Knitted Fabric, American J. Eng. Res., 2014, 3(9),87-90. DOI: $10.6084 / \mathrm{m} 9$. figshare.1171104

5. C. Dette, M. A. P.Osario, C. S. Kley, P. Punke, C. E. Patrick, P. Jacobson, F. Giustino, S. J. Jung, K. Kern, $\mathrm{TiO}_{2}$ Anatase with a Bandgap in the Visible Region, Nano Lett., 2014, 14, (11), 6533-6538. https://doi.org/10.1021/nl503131s

6. T. Luttrell, S. Halpegamage, J. Tao , A. Kramer, E. Sutter and M. Batzill, Why is Anatase a Better Photocatalyst than Rutile - Model Studies on Epitaxial $\mathrm{TiO}_{2}$ Films, Sci. Rep., 2014, 4. 1-8. DOI: $10.1038 /$ srep 04043

7. S. H. Valencia, J. M. Marin, G. Restrepo, Study of the Bandgap of Synthesized Titanium Dioxide Nanoparticules Using the Sol-Gel Method and a Hydrothermal Treatment, Open Mater. Sci. J., 2010, 4, 9-14.

DOI:10.2174/1874088X01004020009
8. D.A. H. Hanaor, C. Sorrell, Review of the Anatase to Rutile Phase Transformation, J. Mater. Sci., 2011, 46, 855-874. 10.1007/s10853-010-5113-0

9. M.J. Gazquez, J. P. Bolivar, R, G. Tenorio, F. Vaca, A Review of the Production Cycle of Titanium Dioxide Pigment. Mater. Sci. and Appl. 2014, 5, 441-458. http://dx.doi.org/10.4236/msa.2014.

10. M. Anbia, F. Ahmadian, M. Rezaie, Preparation of Titanium Dioxide Nanostructure from Ilmenite Through SulfateLeaching Process and Solvent Extraction by D2EHPA, J. Iran. Chem. Soc., 2018, 15, 11. DOI: 10.1007/s13738-018-1441-9

11. T. H. Nguyen, M.S. Lee, A Review on the Recovery of Titanium Dioxide from Ilmenite Ores by Direct Leaching Technologies, Mineral Process. and Extract. Metal. Rev., 2019, 40, 231-247. https://doi.org/10.1080/08827508.2018.1502668

12. V.S. Gireesh, V.P. Vinod, S. Krishnan Nair, G. Ninan, Catalytic Leaching of Ilmenite Using Hydrochloric Acid: A Kinetic Approach, Int. J. Min. Process., 2015, 134, 36-40. DOI: 10.1016/j.minpro.2014.11.004 